\title{
ANTICIPATING NEW-HIGHWAY IMPACTS: OPPORTUNITIES FOR WELFARE ANALYSIS AND CREDIT-BASED CONGESTION PRICING
}

\author{
Kara M. Kockelman \\ Professor \& William J. Murray Jr. Fellow \\ Department of Civil, Architectural \& Environmental Engineering \\ The University of Texas at Austin \\ Austin, Texas 78712 \\ (512) 471-0210 \\ kkockelm@mail.utexas.edu \\ Jason D. Lemp \\ Cambridge Systematics \\ 9015 Mountain Ridge, Suite 210 \\ Austin, TX 78759 \\ jlemp@camsys.com
}

The following paper is a pre-print and the following publication can be found in

Transportation Research Part A, 45 (8):825-838, 2011

Key Words: highway investment decisions, congestion pricing, traveler welfare analysis, optimal tolls

\begin{abstract}
Pricing of roadways opens doors for infrastructure financing, and congestion pricing seeks to address inefficiencies in roadway operations. This paper emphasizes the revenue-generation opportunities and welfare impacts of flat-tolling schemes, standard congestion pricing, and credit-based congestion pricing policies. While most roadway investment decisions focus on travel time savings for existing trips, this work turns to logsum differences (which quantify changes in consumer surplus) for nested logit specifications across two traveler types, two destinations, three modes and three times of day, in order to arrive at welfare- and revenue maximizing solutions. This behavioral specification is quite flexible, and facilitates benefit-cost calculations (as well as equity analysis), as demonstrated in this paper.

The various cases examined suggest significant opportunities for financing new roadway investment while addressing congestion and equity issues, with net gains for both traveler types. Application results illustrate how, even after roadway construction and maintenance costs are covered, receipts may remain to distribute to eligible travelers so that typical travelers can be made better off than if a new, non-tolled road had been constructed. Moreover, tolling both routes (new and old) results in substantially shorter payback periods (5 vs. 20 years) and higher welfare outcomes (in the case of welfare-maximizing tolls with credit distributions to all travelers). The tools and techniques highlighted here illustrate practical methods for identifying welfare-enhancing and cost-recovering investment opportunities, while recognizing multiple user classes and appropriate demand elasticity across times of day, destinations, modes and routes.
\end{abstract}




\section{INTRODUCTION}

Reliable and efficient transport is an essential ingredient in the economic prosperity of regions and countries. Traffic congestion hinders the movement of people and goods, but is on the rise, due to increases in population, and overall travel demand regularly outstripping system additions. Funding for capacity expansion and roadway maintenance through traditional means is limited, resulting in a quest for relatively innovative methods to finance new roads. While the use of tolls to generate such funding is not a new idea, toll financing is becoming an increasingly important option (USDOT 2005, U.S. GAO 2006, Samuel 2007).

The basic theories behind policies of roadspace rationing, optimal taxation, and congestion pricing are nothing new either. (See, e.g., Pigou 1920, Knight 1924, and Vickrey 1963.) As with consumption of scarce resources, the congestion of capacity-constrained infrastructure leads naturally to higher prices, in the presence of private markets, guided by an invisible hand. Whether the infrastructure consists of hotel rooms, aircraft, telephone lines, movie theatres, or roadways, the marginal costs of facility expansion are optimally borne by those who most benefit from the marginal investment. In most cases, there are many potential customers with high values of time who are willing to pay a premium in order to moderate (and/or eliminate) travel delays.

Here, a policy of credit-based congestion pricing ( $\mathrm{CBCP}$ ) is featured, and compared to other, toll and no-toll options, in the context of roadway financing. As proposed by Kockelman and Kalmanje (2005), CBCP is a revenue-neutral strategy that seeks to overcome the negative equity impacts of congestion pricing (CP) by allocating toll budgets to eligible travelers periodically. In its most basic form, the "average" driver pays nothing, while frequent, long-distance, peakperiod drivers subsidize others, in effect paying them to stay off congested roads (or switch to less congesting modes, such as the bus). However, in the context of financing new capacity, opportunities for CBCP credits may be exhausted by infrastructure costs. This work offers a closer look at policy options and implications in a small network example in which demand elasticity across destinations, modes, times of day, and routes are recognized in a behaviorally consistent and rigorous way, via a four-level nested logit model structure. Such specifications allow more realism and flexibility in the choice process than most existing road-pricing work, which neglects opportunities for substituting destinations, and/or routes, modes, and times of day for travel.

\section{RELATED LITERATURE}

As evident in the work of countless transport economists (see, e.g., Walters [1961], Vickrey [1969], Arnott et al. [1994], Verhoef [2000], and Small and Verhoef [2007]), marginal social cost (MSC) pricing should be very effective in reducing (recurrent) congestion. MSC toll levels ensure that each traveler pays a cost equal to the cost of the added delay that he/she imposes on other road users (i.e., the marginal external cost of congestion). When MSC tolls are applied on all network links and modes, the socially optimal, or "first-best", solution is achieved (Small and Verhoef 2007). Moreover, there is typically a rather simple analytic solution for finding the socially optimal tolls on each network link if one is dealing with rather standard link cost functions such as the Bureau of Public Roads (BPR) link performance function. (See, e.g., Small and Verhoef 2007.) Of course, there are numerous reasons that make the "first-best" solution infeasible from a practical sense (e.g., it may be infeasible to toll all links or it may be infeasible 
to differentiate tolls across different classes of users, to name a couple), and much literature has been devoted to the formulation of "second-best" pricing strategies (see e.g., Levy-Lambert 1968, Marchand 1968, Verhoef et al. 1996, Arnott and Yan 2000, Verhoef 2002a and 2002b, among many others). As expected, a key result is that "second-best" tolls differ from "first-best" tolls (Verhoef 2002b).

Several studies have investigated roadway financing through tolls. Mohring and Harwitz (1962) showed that under certain conditions, priced roads could be self-financing. Verhoef and Rouwendal (2004) extended this result for a small network example, illustrating that optimal capacity choices throughout a network (assuming equal capacity provision costs anywhere in the network) result in constant optimal toll rates (throughout the network). Verhoef (2007) showed that the socially optimal road could be built and managed through a bidding process involving private firms.

De Palma and Lindsey (2007) examined cost recovery in detail, outlining the cost recovery theorem, which defines the expected level of cost recovery under MSC tolls and optimal capacity. If the marginal cost of adding capacity and user costs are constant (thanks to constant returns to scale), then MSC tolls will produce just enough revenue to cover costs. Of course, these conditions rarely if ever hold in practice (for roadways), due to the non-continuous nature of adding capacity, the presence of heterogeneous users, and demand that varies across time, among other reasons.

Despite the evident merits of roadway pricing, public and political opposition to pricing policies can be intense, for a number of reasons. The public often perceives tolls as a new tax on something that has always been free or paid for at the pump (Kockelman et al. 2009). Further, issues of social (in)equity can be very important to the public (U.S. GAO 2006), since not all are willing or able to pay the tolls that would emerge under potential policies. In particularly congested corridors (e.g., heavily used bridges and other key bottlenecks), tolls could quickly rise to $\$ 1$ USD or more per mile of vehicle travel ${ }^{1}$. Equity considerations may take center-stage in related policy debates. The distributed burdens and benefits of congestion pricing make regressive outcomes a key drawback. Researchers have suggested different solutions to overcome this, including commuter credits (Small, 1992), income tax reduction (Parry and Bento, 2001), FAIR lanes (DeCorla-Souza, 1995), roadspace rationing (Daganzo, 1995, Nakamura and Kockelman 2002), and providing 'mobility rights' (Viegas, 2001) to name a few. As noted earlier, Kockelman and Kalmanje (2005) proposed a somewhat different solution, called credit-based congestion pricing (CBCP).

Kalmanje and Kockelman (2004) examined the traffic and traveler-welfare impacts of an Austin, Texas application of CBCP. And Gulipalli and Kockelman (2008) conducted a similar study for the Dallas-Fort Worth Metroplex, which also closely examined implementation costs and vehicular emissions. Their models of travel behavior segmented the typical workday into five times of day, using static traffic assignment during those periods. In both cases, two MSC tolling systems were examined: pricing of the entire network (by time of day, in accordance with marginal social costs, under a single assumed value of travel time), and pricing only of major highways (primarily freeways). Short- and long-term scenarios were examined, holding job locations (work trips) fixed at no-pricing levels and then allowing those to vary, along with

\footnotetext{
${ }^{1}$ Marginal costs of $\$ 1$ per mile or more emerge when using standard BPR parameter values in instances where demand-to-capacity ratios lie above 1.0 and values of time are on the order of $\$ 10$ per vehicle-hour (or more).
} 
destination choices of all other trip types. Measures of equivalent variation for consumer surplus changes pre- and post-pricing were examined, in order to ascertain the spatial and demographic distribution of benefits. As expected, speed improvements were substantial, as travelers shifted destination, mode, route and time of day choices. The analyses resulted in positive estimates of net benefits (net of implementation costs) for the great majority of residents $(95 \%$ of budgeteligible $^{2}$ travelers in the DFW study ${ }^{3}$ ). In order to estimate these net benefits, money-scaled differences in logsums were used. As per Small and Rosen (1981) and Ben-Akiva and Lerman (1985), these represent measures of equivalent variation (in other words, the equivalent income effect of a switch to marginal-cost roadway pricing). Such values are computed after a uniform credit distribution to all registered vehicle owners or all workers (both representing two-thirds of the population). And they apply to the "average" traveler (which spanned 6 household classes, on the basis of income and vehicle ownership, in the DFW case). However, pricing at marginal social cost is not optimal when other, related goods are not priced similarly. Thus, in the case of major-highway-only pricing, many substitute routes are non-tolled, so MSC pricing is suboptimal. Lower toll levels would be more appropriate in such instances, and more benefits (relative to MSC pricing with unpriced substitutes) may emerge. (See, e.g., Dial [1999] and Penchina [2003].)

While marginal-cost pricing should be effective in reducing congestion, its value for raising infrastructure funds in non-urban areas and addressing other issues (such greenhouse gas emissions) is not so clear. Of course, using the same electronic toll collection (ETC) systems that would be required for such pricing, one may rather easily incentivize the use of more fuel efficient vehicles with lower emissions. Two key questions then emerge: What are the costs of tolling infrastructure in this way, and what toll rates and credit levels are appropriate?

Kockelman et al. (2005) concluded that RFID toll tags are the best toll technology for the near term, allowing local pricing of road use ${ }^{4}$. As summarized in Gulipalli and Kockelman (2008), the present cost of RFID transponder stickers lies at and/or below \$1 per user. When permanently attached to one's vehicle, stickers of this type allow operators to identify vehicles, enabling pricing of emissions and other negative externalities. Though offering fewer anonymity protections, such permanent tags are popular for toll administration, serving as the standard option for residents of the Austin, DFW, and Houston regions. Of course, roadside readers and gantry systems (to hang video cameras and readers), vehicle-classification curtains, and other system components are not inexpensive. Nevertheless, they represent a one-time cost. Over a system's lifetime, Gulipalli and Kockelman (2008) predicted these to be small in comparison to observed system administration costs, which average \$100,000 USD per lane-mile in current U.S. systems. Such costs are likely to fall over time, thanks to growing experience and technological innovations (e.g., paperless billing and more robust reader systems).

\section{METHODOLOGY}

\footnotetext{
${ }^{2}$ In Gulipalli and Kockelman's (2008) analysis, budget eligibility was based on vehicle registrations, so $70 \%$ of the region's 3 million residents were assigned credits.

${ }^{3}$ Implementation costs were not examined in the earlier, Austin study, and so were not applied. With a zeroimplementation-cost assumption, virtually all "average" travelers in the Austin study were predicted to benefit under such a policy. In reality, implementation costs would reduce credit levels, and great heterogeneity exists in any regional population, resulting in significant benefits for some, and no doubt significant costs for others.

${ }^{4}$ In the longer term, global positioning system (GPS) technology may be best.
} 
While urban-system analyses, such as the Austin and DFW case studies described above, are very useful - and complex, they can obscure salient features of the policy under question, and they require second-best solutions: finding optimal toll levels in such system-level analyses is not feasible if some roads or modes are not tolled or otherwise imperfectly priced and multiple user classes exist. To illuminate key features of a CBCP policy in the context of road financing, an example of multiple alternatives for travel between a single origin and two destinations is used here. The alternatives include the choice of destination, mode (auto, bus, or walk), time-ofday (AM peak, PM peak, and off-peak), and route. Figure 1 details the layout of this idealized network. The stylized network retains significant choice flexibility (across destinations, modes, times of day, and routes) while providing relative transparency in findings and model specification (by limiting the total number of alternatives).

Such choice flexibility is a key difference between the methods used here and those applied in most prior pricing research (both first- and second-best related pricing). While some prior work considers elasticity in demand functions between given zone pairs (e.g., Maruyama and Sumalee 2007), most studies consider only route choice (e.g., Braid 1996, Dial 1999, Liu and McDonald 1999, and Penchina 2003). Recognition of destination choice is a major piece of the behavioral puzzle, and it allows for very natural (in that it fits into the framework of random utility maximization) elasticity effects in trip generation, avoiding a presumption of fixed trip tables. Of course, there are examples where such choice flexibility has been used in welfare analyses (see, e.g., Kalmanje and Kockelman 2004 and de Jong et al. 2007), but these studies focus on the welfare analysis rather than optimal toll levels.

Using a nested logit specification (see, e.g., Ben-Akiva and Lerman 1985), so that clusters of similar options exhibit correlated error terms, and making some assumptions about cost and time sensitivity, as well as scale parameters, one can compute flows for each alternative. There are four distinct choice dimensions being modeled here, so the nesting structure exhibits three embedded nests. At the lowest level is route choice, above that is time-of-day choice, mode, and destination at the highest level. Reasonable behavioral parameter values were selected to characterize preferences. Figure 2 shows the overall nesting structure of the model, and the associated scale parameters (the $\mu$ values).

Two destination options (A and B) are available for each user. Destination A represents a location close in proximity to the origin $(1$ mile), while destination $B$ is much farther away ( 8 miles). However, the attractiveness of destination A is much less than that of B (10 versus 200). Further, the free-flow speed to A via automobile is only $10 \mathrm{mph}$, as compared to $60 \mathrm{mph}$ to B. The presence of destination $\mathrm{A}$ is important for allowing destination choice flexibility; it represents a collection of relatively small-scale local choices (e.g., local shopping, services, and recreational opportunities), which would be mostly attractive because of their proximity.

The two routes to destination B (existing and new) ${ }^{5}$ are assumed to be identical in their physical characteristics, and the Bureau of Public Roads (BPR) link performance function (Equation 1) was used to compute travel times as a function of free-flow times, capacities, and volumes, with alpha $(\alpha)$ and beta $(\beta)$ parameters of 0.85 and 5.5, respectively (as suggested by Martin and McGuckin (1998)):

\footnotetext{
${ }^{5}$ Note that in the base scenario, it is assumed that only one of these two routes to destination B exists (it does not matter which one since they are identical in their characteristics). In all other scenarios, both routes exist.
} 


$$
t_{l}=t_{\text {free, },}\left(1+\alpha\left(v_{l} / c_{l}\right)^{\beta}\right)
$$

where $t_{l}$ is travel time on link $l, t_{\text {free,l }}$ is free-flow travel time on link $l_{3} v_{l}$ is demand for link $l$, and $c_{l}$ is link l's capacity flow volume.

For destination A, capacity is assumed to be unlimited, which is reasonable when assuming that these trips use the local street network with multiple paths (and relatively low demand, as compared to supply).

In the second level of the nest, three mode alternatives are available, though the walk mode is only available to destination A (since a distance of 8 miles to B is assumed too far for someone to reasonably consider walking). Walk speed is assumed to be $4.47 \mathrm{mph}$, and bus speed is assumed to be the same as the auto mode ${ }^{6}$. However, a flat 15 min penalty is added to bus times to represent its added wait, access, and egress times. Further, the bus fare is set at $\$ 0.50$ per trip (the case of Austin's CapMetro system), and buses on the network are assumed to be equivalent to 2.0 passenger cars (as suggested by the Highway Capacity Manual [TRB 2001]), and buses are assumed to ride "full", at 20 persons of capacity. For the auto mode, a fixed operating cost of $\$ 0.20 /$ mile is assumed (which is less than the American Automobile Association [AAA 2006] recognizes for full-cost accounting of vehicle ownership and use but about $35 \%$ more than current gas costs, assuming a $20 \mathrm{mi} /$ gallon vehicle). Last, in calculation of utilities for each alternative, alternative specific constants (ASCs) are assumed for each mode: 0.0 for auto, -1.1 for bus, and -1.3 for walk. ${ }^{7}$

The last two levels of the nesting structure are for time-of-day (TOD) and route choices (though choice of route is only available to those driving to destination B). Three TOD alternatives are available and link capacities to destination B are assumed to vary by the number of hours in each time period (which assumes uniform assessment of all traffic within each period). AM peak is assumed to last 3 hours (6-9 am) and PM peak is assumed to last 4 hours (3-7 pm). Instead of giving the off-peak (OP) period the remaining 17 hours of the day, it is assumed that most OP travel will occur between the AM and PM peaks; thus, the OP period lasts 6 hrs. If 2,000 passenger cars per hour per lane (pcphpl) is assumed for freeway capacity, and each route to B has two lanes, then capacities on both routes are the same for each TOD: 12,000 passenger cars equivalents in the AM, 24,000 in the OP, and 16,000 in the PM. In computing utilities, ASCs for each TOD alternative are assumed to be $0.0,-0.3$, and 0.2 for the AM peak, OP, and PM peak, to reflect relative preference for travel during the PM and then AM periods, respectively.

Several other assumptions are needed here as well. The total number of system users is assumed to be 125,000, segmented into two groups. Low value of travel time (VOTT) users make up half of the population (with a \$6/hour VOTT), and high VOTT users make up the other half (with a $\$ 12 /$ hour VOTT) ${ }^{8}$. Finally, it is important to discuss the scale parameters (which are the inverse of the inclusive value coefficients) in each level of the nested model. While scaling parameters need not be the same for two different nests at the same level in the nesting structure, all were

\footnotetext{
${ }^{6}$ In the case of travel to destination B, buses are assumed to travel on route 2, which is the route selected for tolling in the model applications. However, bus users do not pay tolls.

${ }^{7}$ Values were selected to represent reasonable preference structures and are simply for illustrative purposes.

${ }^{8}$ Small and Verhoef (2007) suggest that VOTTs vary widely, between 20 and $90 \%$ of wage rate, depending on trip purpose, schedule constraints, and such. The assumptions used here may reflect relatively low and high income travelers, with wage rates of $\$ 15$ and $\$ 30$ per hour, respectively, and VOTTs equaling $40 \%$ of wage rate.
} 
assumed to be the same here for simplicity. For example, the scale parameters across TODs for walk mode to A are assumed to be the same as the scaling parameter across TODs for bus mode to B. Consistent with McFadden's random-utility theory the scale parameters for the route choice, TOD, mode and destination choice nests were assumed to be 1.8, 1.6, 1.4, and 1.2, respectively. In contrast to most nested logit specifications (where the top level nest enjoys a 1.0 scale factor), the top level scaling parameter is assumed here to be 1.2. The reason for this is that the coefficient on cost in the utility equations is set equal to -1 (as will be shown below). In this way all top-level utility values are in terms of dollars already. ${ }^{9}$

As shown in Figure 2, scale parameters $\left(\mu_{1}\right)$ of 1.8 in the lowest nest (driving to destination B via route 1 or route 2$), 1.6\left(\mu_{2}\right)$ in the next lowest nest (AM versus PM versus OP TOD), $1.4\left(\mu_{3}\right)$ in the second highest level nest (walk versus bus versus auto), and $1.2\left(\mu_{4}\right)$ in the upper level nest (destination A versus destination B) were assumed. These are the inverse of inclusive value coefficients, essentially, and they reflect the degree of substitution that occurs between nested alternatives versus alternatives outside the nest. The greater the scale parameter, the greater the substitution between nested alternatives, versus other alternatives. These are falling (from the lowest to the highest level nest) and the inverse of each lies between 0 and 1, consistent with random utility maximization (Ben-Akiva and Lerman 1985). With all these assumptions in place, equilibrium shares of destination, mode, TOD, and route choices, and equilibrium travel times were estimated for a variety of pricing scenarios. The associated equations, for generalized trip costs, systematic utilities, inclusive values (scaled logsums) of the nested choices and choice probabilities are as follows:

$$
\begin{aligned}
& G C_{i, d m p r}=\operatorname{VOTT}_{i} \cdot t_{d m p r}+\tau_{d m p r}+O C_{d m p r} \\
& V_{i, d m p r}=\left[\ln \left(A t t r_{d}\right)-\ln \left(A t t r_{B}\right)\right]+A S C_{m}+A S C_{p}-G C_{i, d m p r} \\
& \Gamma_{i, d m p}=\frac{1}{\mu_{1}} \ln \left[\exp \left(\mu_{1} V_{i, d m p, \text { routel }}\right)+\exp \left(\mu_{1} V_{i, d m p, \text { route } 2}\right)\right] \\
& \Gamma_{i, d m}=\frac{1}{\mu_{2}} \ln \left[\exp \left(\mu_{2} \Gamma_{i, d m, A M}\right)+\exp \left(\mu_{2} \Gamma_{i, d m, \text { OP }}\right)+\exp \left(\mu_{2} \Gamma_{i, d m, P M}\right)\right] \\
& \Gamma_{i, d}=\frac{1}{\mu_{3}} \ln \left[\exp \left(\mu_{3} \Gamma_{i, d, \text { Walk }}\right)+\exp \left(\mu_{3} \Gamma_{i, d, \text { Bus }}\right)+\exp \left(\mu_{3} \Gamma_{i, d, A u t o}\right)\right] \\
& \operatorname{Pr}_{i, d}=\frac{\exp \left(\mu_{4} \Gamma_{i, d}\right)}{\sum_{l \in D} \exp \left(\mu_{4} \Gamma_{i, l}\right)} \\
& \operatorname{Pr}_{i, d m}=\operatorname{Pr}_{i, d} \frac{\exp \left(\mu_{3} \Gamma_{i, d m}\right)}{\sum_{l \in M} \exp \left(\mu_{3} \Gamma_{i, d l}\right)}
\end{aligned}
$$

\footnotetext{
${ }^{9}$ An equivalent formulation emerges when setting the top level scaling parameter to 1.0 (as is customary) and adjusting other parameters accordingly. Such a formulation will require subsequent conversion of utility values to dollars, however.
} 


$$
\begin{gathered}
\operatorname{Pr}_{i, d m p}=\operatorname{Pr}_{i, d m} \frac{\exp \left(\mu_{2} \Gamma_{i, d m p}\right)}{\sum_{l \in P} \exp \left(\mu_{2} \Gamma_{i, d m l}\right)} \\
\operatorname{Pr}_{i, d m p r}=\operatorname{Pr}_{i, d m p} \frac{\exp \left(\mu_{1} \Gamma_{i, d m p r}\right)}{\sum_{l \in R} \exp \left(\mu_{1} \Gamma_{i, d m p l}\right)}
\end{gathered}
$$

Here $G C$ is the generalized cost, $V$ stands for systematic utility of the alternative (as measured in dollars), $\Gamma$ denotes the inclusive value or expected maximum utility for an upper level alternative, $\operatorname{Pr}(\cdot)$ represents the probability of a particular choice, $i$ denotes user group (either low or high VOTT), $d$ stands for the destination of interest (either A or B), $m$ represents the mode of interest (walk, bus, or auto), $p$ denotes the TOD (AM, OP, or PM), $r$ is the route (either 1 or 2$)^{10}, D$ is the set of destination alternatives, $M$ is the set of mode alternatives, $P$ is the set of TOD alternatives, and $R$ is the set of route alternatives. Here, VOTT denotes the value of travel time for the associated traveler group, $\mu_{1}, \mu_{2}, \mu_{3}$, and $\mu_{4}$ serve as the scaling parameters for the route, TOD, mode, and destination nests, respectively, $\tau$ represents out-of-pocket charges (for toll or bus fare) and has no coefficient (so that utilities are in dollars ${ }^{11}$ ), $O C$ is the out-of-pocket operating expenses (set to zero for bus and walk modes), $t$ denotes the travel time, ASC represents the alternative specific constants for mode and TOD alternatives, and Attr is the attractiveness value of each destination.

Estimates of the change in consumer surplus $(\triangle \mathrm{CS})$ of each tolled scenario were computed as well. For a model such as the one formulated here, normalized logsums of systematic utilities provide the basis for consumer surplus calculations. When divided by the marginal utility of money (which in this case is 1 [as explained in footnote 11]), the consumer surplus change from one scenario to another can be computed simply as logsum differences between any two scenarios (see, e.g., Small and Rosen 1981, Ben-Akiva and Lerman 1985, de Jong et al. 2007, and Zhao et al. 2008). The CS computation is as follows:

$$
\Delta C S_{i}=\frac{1}{\mu_{4}}\left(\ln \left[\sum_{k \in D} \exp \left(\mu_{4} \Gamma_{i, k}^{1}\right)\right]-\ln \left[\sum_{k \in D} \exp \left(\mu_{4} \Gamma_{i, k}^{0}\right)\right]\right)
$$

This is the difference in expected net benefits per traveler type $i$ for scenario 1 relative to the base scenario 0 . In general, the $\Delta \mathrm{CS}$ can be measured between any two scenarios, but we will look primarily at the change in consumer surplus as measured in reference to the base scenario where only one of the two routes to destination B is available. In other words, the base scenario is a "do nothing", scenario where no new roadway is built to destination B. Equations 2 through 11 were applied for both traveler types, recognizing the distinctive values of time scenarios examined.

\section{APPLICATION RESULTS}

\footnotetext{
${ }^{10}$ Two routes exist only if auto mode and destination B are chosen. In the other cases, route 2 can simply be assumed to have some arbitrarily large disutility (or travel cost) associated with it such that route 2 is not chosen.

11 Since utility is unobserved, forcing the cost coefficient to equal one necessitates the use of two (non-unitary) scale factors (one for each nest). This offers greater transparency in dimensioning, but is in some contrast to most NL specifications (where $\mu$ is set equal to 1 in the upper [or lower] nest).
} 
An assortment of tolled and non-tolled scenarios was investigated. The base scenario is such that only one of the two routes to destination B exists, and this route is not tolled. In addition, another non-tolled scenario is constructed such that both routes to destination B exist, but neither is tolled (i.e., build a new road without tolls). Six distinctive tolled scenarios were also considered, for a total of eight scenarios ${ }^{12}$. The simplest of these involve the building of a new, 2-lane road with a flat toll assessed (both $\$ 0.05$ per mile and $\$ 0.10$ per mile tolls are considered here). Optimal toll levels on the new, 2-lane road were sought, to maximize expected net benefits, across all 125,000 travelers (relative to the non-tolled scenario). Moreover, this scenario was extended to the case where optimal toll levels are assessed on both routes to destination B. Finally, revenue maximizing tolls were considered on the new, 2-lane route as well as on both routes to destination B. The results of these applications are largely consistent with previous work on first- and second-best pricing regimes, like that of Small and Verhoef (2007). And the results emerge from relatively straightforward (at least in this relatively simple, idealized setting) network equilibration and optimization procedures. Moreover, for each scenario, equilibrium was reached between traveler choices and network travel times and costs. It should be noted that capacity was assumed fixed for the new toll road in all scenarios to ensure consistency with scenarios where no optimization was sought (i.e., the no-toll and fixed-toll scenarios).

\section{Traveler Choices and Network Effects}

Under the above assumptions, base conditions (where only one route to destination B exists) result in volume-to-capacity (V/C) ratios for peak and off-peak periods of 1.08 (for both AM and PM peaks) and 0.98, respectively, to destination B. This results in 19 minute and 15 minute peak and off-peak travel times to destination $\mathrm{B}$, which are quite high relative to its 8-minute free-flow travel time.

Of course, what is of interest is how this compares to scenarios in which a second route (to destination B) is added (essentially doubling corridor capacity). In each case of an added route to destination $\mathbf{B}$, substantial delay reductions emerge. When the new route is not tolled, $\mathrm{V} / \mathrm{C}$ ratios, and thus travel times, to $\mathrm{B}$ are lower. Travel times are just under 14 minutes in the peak periods and 10 minutes in the off-peak period (Table 1), saving travelers about 5 minutes per trip in all TODs. If a flat toll of $\$ 0.40$ (equivalent to $5 \phi$ per mile) is assessed on the new route to destination $\mathrm{B}$, lower $\mathrm{V} / \mathrm{C}$ ratios are experienced on the tolled route (in comparison to the nontolled case); and $\mathrm{V} / \mathrm{C}$ ratios are higher on the non-tolled route (as compared to the non-tolled case), but lower than the base (no-build) scenario. If a flat toll of $\$ 0.80$ (equivalent to $10 \phi$ per mile) is assessed on the new route to $\mathrm{B}$, similar results emerge, but with more significant differences. Thus, in comparison to the non-tolled scenario, travel times to destination B in these two tolled scenarios fall by about 2 and 3.5 minutes per trip in peak periods (for the $5 \varnothing$ and $10 \varnothing$ per mile settings, respectively, as shown in Table 1). However, traffic shifts to the non-tolled route, where travel times rise.

\footnotetext{
${ }^{12}$ These scenarios are in no way exhaustive and simply serve to illustrate key policy cases. In reality, an infinite number of scenarios could be run, with different new-route capacities, parameter and future traffic growth assumptions, and so forth. As mentioned earlier in the paper, other costs and benefits could also be considered, such as emissions, crashes, bus expenditures, and so forth, for a truly comprehensive approach to transportation investment decision-making.
} 
In the case of welfare maximizing tolls ${ }^{\mathbf{1 3}}$, two scenarios were investigated: one where only the new route to destination $B$ is tolled and one where both the new and old routes to destination $B$ are tolled. In the case of one tolled route, the welfare maximizing toll on that route is found to be $\$ 0.89$ in the AM peak, \$0.91 in the PM peak, and \$0.26 in the off-peak period (Table 1). Both peak periods' optimal tolls are higher than the flat tolls considered above, while the off-peak period toll is somewhat less, since it is less attractive to travelers (and thus was assigned a negative ASC). These tolls result in travel times on the new route that are almost the same for peak and off-peak periods (just 9 minutes during the off-peak and about 9.5 minutes during the two peaks), in clear contrast to the flat tolls discussed above. If welfare maximizing tolls are charged on both routes to destination $\mathrm{B}$, tolls rise (to about $\$ 1.10$ to $\$ 1.20$ in the peak periods and about $\$ 0.60$ in the off-peak period, as shown in Table 1, and consistent with Small and Verhoef's [2007] results for second-best congestion pricing). The reason tolls rise in this scenario (as compared to welfare maximizing tolls on a single route) is that MSC tolls are required, since this is a first-best solution. When only a single route is tolled, MSC tolls are inefficient in a welfare-maximizing sense, and toll levels will be lower (since an unpriced alternative is available). While tolls may be high, travelers enjoy significant travel time benefits when driving to destination B. No travelers destined for B experience more than a 9.5 minute travel time.

If road managers instead wish to maximize revenue on the new route, optimal tolls will be $\$ 1.33$ in the AM peak, \$0.99 in the off-peak, and \$1.35 in the PM peak (Table 1). If one maximizes revenues by tolling both routes to destination $B$, the lowest travel times emerge, since fewer travelers choose destination $B$, due to tolls on the order of $\$ 1.60$ to $\$ 1.70$ in the peak periods and $\$ 1.35$ in the off-peak period (as shown in Table 1), much higher than in any of the other scenarios. High tolls, such as these, result in a substantial reduction in VMT. In fact, maximizing revenue on both routes is the only scenario in which VMT drops relative to the base scenario (5.4\% less). All other scenarios see a substantial increase in VMT relative to the base, ranging from a $24.6 \%$ increase in the case of welfare maximizing tolls on both routes to a $53.4 \%$ increase when neither route to destination B is tolled.

Figures 3 and 4 show the shares of low- and high-VOTT travelers, respectively, choosing destination-mode alternatives under each of the eight scenarios. In the base scenario, $90 \%$ of low-VOTT travelers drive (34\% to destination A and 56\% to destination B) and $96 \%$ of highVOTT travelers drive (67\% to destination A and 30\% to destination B). Outside of the case of welfare maximizing tolls on both routes, no other scenario comes close to the percentage of travelers choosing the drive option to destination A for either low- or high-VOTT travelers. Of course, this is due to the fact that destination B is more attractive and adding capacity results in more travelers choosing their preferred destination.

Another interesting result evident in Figures 3 and 4 is transit usage across the tolled scenarios, especially for low-VOTT travelers. In these scenarios, one sees greater transit usage to destination B, reaching a maximum at about $25 \%$ of low-VOTT travelers (in the welfaremaximizing toll-both-routes scenario). The reason for this is two-fold: tolls on one or both routes to B cause users to switch modes while reducing bus travel times, thus enhancing the bus mode's appeal.

\footnotetext{
${ }^{13}$ Here, welfare maximizing tolls refer to toll levels that result in the maximum social welfare, which includes traveler-perceived costs and benefits, along with revenues generated.
} 
Another set of meaningful results emerge from trip-timing choices as summarized in Table 2. Pricing incentives help shift traffic to less congested TODs, in order to better balance demand and supply. Table 2 shows the percentages of travelers choosing destination B in each scenario for each TOD, reductions in these percentages (versus the no-toll added-capacity scenario), the percent of travelers choosing the new route to destination B in each TOD, and the reductions in these percentages (versus the no-toll added-capacity scenario). Such results provide a good idea of the differences one might expect for each tolling scenario in comparison to the no-toll case. Restricting the discussion to the four tolling scenarios where only the new road is tolled, one finds that the only scenario that in fact shifts traffic to the off-peak is the one in which tolls are set to maximize welfare. In the other cases, only minor shifts away from destination B are found in the peak periods (less than $1 \%$ change for both flat toll scenarios and about $5 \%$ change for the revenue-maximizing-toll-scenario), but reductions in travel to B in the off-peak are about $6 \%$, $16 \%$, and $18 \%$ for $5 \phi /$ mile toll, $10 \phi /$ mile toll, and maximum-revenue toll, respectively. If tolls are set to maximize welfare, however, one finds $4 \%$ reductions in peak-period travel to destination B and only $1.5 \%$ reduction in off-peak travel. By definition, the net social benefit or welfare maximizing toll works to better utilize corridor capacity across TODs.

The preceding discussion highlights traveler choices and network effects for each of the scenarios investigated. While such comparisons highlight some of the key consequences of each scenario, they do not yet address the question of how to finance new highway infrastructure. The following section deals with the welfare impacts of each scenario, relative to the costs and payback periods associated with building and operating the new road.

\section{Welfare Results}

Equation 11 specifies equivalent variation or average consumer surplus change as measured relative to the one-route (to destination B) base scenario, in units of dollars per traveler. A positive consumer surplus change means that users benefit (on average) from the policy, whereas a negative consumer surplus change indicates user losses. In addition to consumer surplus, revenues resulting from each tolling scenario are considered here. If those revenues are distributed equally to each traveler, as is the case with standard CBCP, such travel credits add to changes in consumer surplus. (Of course, if revenues are not distributed to travelers, then they are retained by the toll collector.) Table 3 presents the predicted revenue streams and consumer surplus before and after credits are distributed for each of the scenarios previously discussed. It is important to note here that since capacity to destination $\mathrm{A}$ is assumed to be unlimited (representing a network of local roads), there are no changes in travel times or consumer surplus for those traveling to destination A.

As shown in Table 3, generated revenues range from $\$ 0$ in the Build, No Toll route scenario to $\$ 81,000$ per day in the Revenue Maximizing, Both Routes Tolled scenario. ${ }^{14}$ In discussing consumer surplus, it is not so surprising that in all of the scenarios with the new route to B, consumer surplus change estimates are positive (even for the Revenue Maximizing, Both Routes Tolled scenario where VMT falls), meaning net benefits exist for all travelers even before credits are distributed. This is due to the highly congested conditions of the one-route base scenario, and the simple result that doubling capacity to destination B allows for great congestion relief.

\footnotetext{
${ }^{14}$ Of course, in a symmetric travel and network-capacity situation, where travelers return from destinations A and B, such revenues will double.
} 
The greatest consumer surplus improvements without a CBCP policy emerge in the no-toll scenario (\$0.63 and \$0.69 per traveler per day for low- and high-VOTT travelers, respectively). However, in comparison to a CBCP policy where credits are distributed evenly, this no-toll (nocredits) scenario offers the lowest net benefits for both low- and high-VOTT travelers alike. Even when tolls are set to maximize revenues, low-VOTT travelers fare better than in a no-toll scenario (as long as credits are returned to travelers). These consumer surplus benefits are useful to highlight for all stakeholders. Not only do they suggest that there are benefits for both camps of travelers, but they indicate that low-VOTT travelers may fare best under a CBCP scenario, making good use of the credits afforded them and taking advantage of the higher-speed roadway when needed, while opting for bus when warranted.

Of course, the greatest benefits under a CBCP policy emerge when all "goods" are priced optimally - so that tolls are set to maximize welfare on both routes (EV equals $\$ 0.77$ and $\$ 1.01$ per traveler per day for low- and high-VOTT travelers, respectively). If a no-toll route to destination $\mathrm{B}$ must be provided, the best option emerges from the welfare maximizing scenario with a single route tolled (EV equals $\$ 0.70$ and $\$ 0.81$ per traveler per day for low- and highVOTT travelers, respectively). Clearly, there are benefits for both low-and high-VOTT travelers and high-VOTT travelers benefit more, but the disparity between the two traveler types is larger when both routes are tolled (differences of $\$ 0.11$ with one route tolled and $\$ 0.24$ with both tolled). A similar result is found when tolls are set to maximize revenues. The difference between low- and high-VOTT travelers when one route is tolled is $\$ 0.06$ per traveler per day ( $\$ 0.64$ versus $\$ 0.70$ ) while the difference when both routes are tolled is $\$ 0.24$ per traveler per day ( $\$ 0.65$ versus $\$ 0.89$ ), again supporting the notion that the impacts are more evenly distributed when one route is left non-tolled. The availability of substitute travel options may be essential in maximizing user benefits under tolling (and other) policies while wooing supporters across all demographic classes. Of course, such welfare calculations do not account for the costs of construction of the new facility nor do they account for the operation of tolling technology needed for scenarios with tolling implemented.

\section{Accounting for Highway Costs}

In order to more fully appreciate the scenarios as investment alternatives, it is necessary to recognize the costs associated with building and operating a new roadway. Litman's (2007) review of the literature suggests that freeways in urban areas cost on the order of $\$ 5$ to 10 million per lane-mile, which includes land acquisition, pavement, and intersection reconstruction ${ }^{15}$. Assuming the cost is $\$ 5$ million per lane-mile, an 8 -mile, 2-lane freeway will cost $\$ 80$ million. If one also assumes that routine annual maintenance costs of highways are $\$ 14,000$ per lane-mile ${ }^{16}$ and toll road management costs are $\$ 50,000$ per lane-mile per year ${ }^{17}$, a single toll facility will

\footnotetext{
${ }^{15}$ The costs of building a new road in a non-urban area would be substantially lower. However, the demand associated with a non-urban corridor would likely be lower as well. Thus, in non-urban areas, both costs and revenues would likely be lower than the results presented in this paper. In such cases, welfare benefits generally accrue through the addition of new, faster routes. The methods used here would be directly applicable, and may demonstrate very similar results, in terms of the presence of benefits for both investors and travelers.

${ }^{16}$ Routine annual maintenance costs were based on estimates taken from FDOT (Florida Department of Transportation) in 2003, which range from $\$ 13,100$ to $\$ 14,600$ per lane mile in urban areas. Estimates for rural highways generally are lower (on the order of $\$ 10,200$ to $\$ 10,800$ per lane mile, according to FDOT [2003]).

${ }^{17}$ Total operating expenses and number of toll road lane-miles for NTTA (NTTA, 2003), New Jersey Turnpike Authority (NJTA, 2003), and San Joaquin Hills Transportation Corridor Agency (SJHTCA, 2003) were used to find average management costs for toll roads. All three were on the order of $\$ 100,000$ per lane-mile, but these systems
} 
cost $\$ 1.02$ million per year, and two toll facilities will cost $\$ 1.82$ million per year ${ }^{18}$. Finally, if it is assumed that calculated revenues are for weekdays only and weekend days generate only half that of weekdays, daily revenues can be multiplied by 313 to find yearly revenue streams in each scenario. Given these assumptions, it is possible to perform a cost-benefit analysis of consumer surplus, system expenditures and toll revenues. ${ }^{19}$

The analysis of financing the new road is performed in two ways. First, we assume that all toll revenues go toward the construction and management costs of the new road, after discounting future revenues at $5 \%$ per year ${ }^{20}$. In the scenario where the new road is built without tolls, there are no revenues, but one can still compute costs and traveler benefits, which results in a net benefit of about $\$ 0.52$ per traveler per day (one-way), or $\$ 20.4$ million per year (if costs are financed via a 5-percent 30-year loan. Table 4 presents the results of the analysis, including total and net annual revenues (after covering construction loan costs and toll road management), net annual revenues, and time period it takes to fully recover construction and management costs (assuming an annualized payback). In the case of a flat $5 \phi / \mathrm{mile}$ toll, toll revenues are not enough to cover all costs when future revenues are discounted at $5 \%$. In each of the other scenarios, the repayment period is rather modest (about 20 years or less), with the minimum payback duration (less than 4 years) resulting from tolling of both routes.

Instead, if construction costs were $\$ 10$ million per lane mile in urban areas, rather than $\$ 5$ million, repayment could only be achieved in three of the scenarios (revenue-maximizing tolls on one or both routes and welfare-maximizing tolls on both routes), and repayment periods would range from 53 years (in the case of revenue-maximizing tolls on a single link) to 8.5 years (when revenue-maximizing tolls are assessed on both links). Furthermore, if the corridor were located in a rural area, construction costs would be much lower (on the order of $\$ 2$ million per lane mile instead of $\$ 5$ million), which would result in repayment periods ranging from 1.4 years (in the case of revenue maximizing tolls on both routes) to 10.6 years (in the case of $5 \phi / \mathrm{mile}$ tolls which will not even cover construction costs in an urban setting). Of course, once the costs of building, maintaining, and managing the new road have been recovered, future revenues can go toward any number of things, including credits to travelers, other infrastructure improvements, or the improvement of transit services.

The second analysis assumes that the construction of the new road will be paid for by a 30 -year loan with $5 \%$ interest rate and fixed yearly payments. This amounts to annual payments of approximately $\$ 5.2$ million (not including maintenance and management $\operatorname{costs}^{21}$ ). (In a rural setting with construction costs of \$2 million per lane mile, annual payments would be just \$2.1 million.) The last two rows of Table 4 offer the results of this investment analysis. This includes the additional yearly revenues left over after all payments are made, which is negative in two

\footnotetext{
are mature, and rely on past technology. With new, paperless systems, management costs of $\$ 50,000$ per lane-mile were assumed to be reasonable here.

${ }^{18}$ To ensure comparability, highway maintenance costs are accounted for only on the new facility, in these numbers.

19 For purposes of policymaking, more comprehensive analysis may also be pursued, including computation of bus service subsidies, emissions effects, and crash costs.

${ }^{20}$ While private investors traditionally discount at higher rates, private-public partnerships help reduce risk and facilitate access to lower-interest capital via publicly backed bonds and other financial instruments. Nevertheless, a discount rate of 5\% may be too low for publicly financed tolled roads. Gilroy (2007) suggests that a rate of 7 to $9 \%$ may be more appropriate for such facilities.

${ }^{21}$ Here, yearly maintenance and management costs are subtracted from total yearly revenues to find net revenues, which can then be applied to loan payments.
} 
scenarios, where revenues cannot cover costs. However, a cost-benefit analysis of each scenario yields benefit over cost $(\mathrm{B} / \mathrm{C})$ ratios ranging from a low of 4.20 (in the case of revenuemaximizing tolls on a single route) to a high of 4.96 (in the case of welfare maximizing tolls on both routes). In fact, the no-toll scenario has a higher $\mathrm{B} / \mathrm{C}$ ratio (of 4.76 ) than the welfare maximizing toll on a single route (4.74), which is due to the fact that the no-toll scenario has the lowest associated costs.

If welfare maximizing tolls are assessed on just the new road, a total of about $\$ 1.0$ million per year is available for implementing other transportation policies and/or building new roads. If welfare maximizing tolls are assessed on both routes, almost $\$ 14$ million per year is expected to become available. Of course, this money could be used to credit travelers. Also shown in Table 4 is the amount of available credits per traveler per day. In all of the tolled scenarios, except the $5 \phi /$ mile scenario, additional revenues are left over after this loan is paid off. Moreover, in comparison to the welfare gain of building the new road without tolls (which is about $\$ 0.66$ per traveler per day if construction costs are ignored), the relative cost per traveler of a welfare maximizing toll on the new road is only about $6 \varnothing$ per day (or about $\$ 20$ per year) after the road is fully financed. In contrast, building the new road without tolls will require about $\$ 44$ per traveler per year. If welfare maximizing tolls were enforced on both routes to destination B, credits of about $\$ 0.35$ per traveler per day could be distributed, resulting in a welfare gain of over $5 \notin$ per traveler per day in comparison to the non-financed, no-toll scenario. In other words, after fully financing a new road through welfare maximizing tolls on both the new and existing roads and distributing remaining revenues as credits, the average traveler will be better off than if a new, no-toll road could be built for zero dollars (which, of course, is not possible). In other words, there are toll rates for existing roads that may benefit all stakeholders (on average [see Zhao et al. 2008]), thanks to the distribution of credits, net of costs.

\section{IN SUMMARY}

Much work already exists on the topic of CBCP, in terms of public opinion, implementation costs, and system-level effects in reasonably congested U.S. regions. As shown in eight numerical examples, with two distinctive (and latently heterogeneous) traveler types, congestion levels can be largely reduced in the presence of pricing (even with flat tolls), and consumer surplus effects can be significant, and largely positive, thanks to the provision of credits. And while disparities exist between benefits to low- and high-VOTT travelers, these are lessened when a no-toll or low-tolled option is preserved. Moreover, low-VOTT travelers may fare best under a $\mathrm{CBCP}$ policy that allows them to choose faster, more reliable routes, as needed while offering other alternatives such as bus and walking modes.

Results also indicate that congestion pricing can provide a valuable means to finance new highways along previously congested corridors, though these results may be dampened in the case of a typical rural corridor with moderate demand. In the congested-corridor context examined here, it was found that all but one pricing policy led to revenues that could fully finance the infrastructure costs within 30 years, with excess revenues. Such excess revenues can be used for any number of things. A CBCP policy puts these back in traveler pockets, thereby lessening the negative impact of tolls. Moreover, it was found that it may be possible to fully finance new roads by toll revenues with enough left over to distribute as credits that the average traveler would actually be better off than if a new road was built at no cost and no tolls were charged. While this may be an idealistic scenario, it illustrates an important point that congestion pricing can have quite positive impacts for everyone, especially if toll revenues are 
used wisely. Such calculations are feasible in software packages as common as MS Excel, as long as the route and mode alternatives are relatively compact.

Of course, the analysis provided here illustrates only key concepts in an idealized set of scenarios. Many potential extensions exist, to further highlight key issues involved. For instance, one can imagine no tolls during off-peak periods, thereby allowing for more "free" substitutes. Such a policy may dampen any disparities between low- and high-VOTT user benefits. In addition, one may be interested in the optimal capacity addition to the corridor, and this was done, for the case of welfare maximizing tolls on the new route, resulting in an optimal capacity addition of 3.6 lanes (or 3 lanes if only integer values are allowed). One also may be interested in how results change when external costs (and benefits) of travel are recognized, when uncertainty exists in behavioral parameters (as it invariably does), when one accounts for travel time reliability, and/or when more destinations, modes, routes, TODs and traveler types are permitted; such questions will require more and/or more complicated analysis, but such questions merit investigation when millions - and often billions - of dollars are at stake. The simplified region discussed here assumed that the new roadway capacity would not affect overall traveler demand, but in reality, it likely would (via future land development impacts and latent demand from other, congested areas of the network). Moreover, scenario analysis always involves the forecasting of future demand conditions, which are inherently uncertain. A more comprehensive analysis of optimal toll levels that allows for uncertainty in some or all model parameters and inputs would be possible if certain assumptions are made regarding that uncertainty.

In summary, a variety of pricing policy options exist for those willing to invest in new transportation infrastructure that offers travel time savings. The tools and techniques highlighted here illustrate practical methods for identifying welfare-enhancing and cost-recovering investment opportunities. These techniques recognize demand elasticity across times of day, destinations, modes and routes, which are standard features of most travelers' choice sets but too often neglected in most analysts' toolkits.

\section{ACKNOWLEDGEMENTS}

Graduate student researcher Rui Gao assisted in performing numerous scenarios for this paper's example application, and Drs. Charles Raux and Martin Lee-Gosselin were indefatigable in organizing the valuable 2007 Lyon colloquium on transport, energy and climate change, which initiated this investigation. We appreciate the comments of several anonymous reviewers and the administrative contributions of Ms. Annette Perrone.

\section{REFERENCES}

AAA (2006) Your Driving Costs, 2006. American Automobile Association Public Affairs, Accessed September 2006 from http://www.aaapublicaffairs.com/Main/.

Arnott, R., A. de Palma, and R. Lindsey (1994) “The Welfare Effects of Congestion Tolls with Heterogeneous Commuters,' Journal of Transport Economics and Policy, 28 (2), 139-161.

Arnott, R. and A. Yan (2000) "The Two-Mode Problem: Second-Best Pricing and Capacity," Review of Urban and Regional Development Studies, 12 (3), 170-199. 
Ben-Akiva, M. and S.R. Lerman (1985) Discrete Choice Analysis: Theory and Application to Travel Demand. Cambridge, Massachusetts: MIT Press.

Braid, R.M. (1996) Peak-Load Pricing of a Transport Facility with an Unpriced Substitute. Journal of Urban Economics 40: 179-197.

Cao, X. and P. Mokhtarian (2005) How do individuals adapt their personal travel? A conceptual exploration of the consideration of travel-related strategies, Transport Policy 12: 199-206.

Daganzo, C. (1995). “A Pareto Optimum Congestion Reduction Scheme.” Transportation Research. 29B:139-154.

Davies, J., M. Grant, J. Nenezia, J. Aamidor (2007) US Transportation Sector Greenhouse Gas Emissions: Trends, Uncertainties and Methodological Improvements. Proceedings of the $86^{\text {th }}$ Annual Meeting of the Transportation Research Board, Washington D.C.

de Jong, G., A. Daly, M. Pieters, and T. van der Hoorn (2007) The Logsum as an Evaluation Measure: Review of the Literature and New Results. Transportation Research Part A, 41, 874889.

de Palma, A. and R. Lindsey (2007) "Transport User Charges and Cost Recovery," Research in Transportation Economics 19: 29-57.

DeCorla-Souza, P. (1995). "Applying the Cashing Out Approach to Congestion Pricing." Transportation Research Record, 1450, 34-37.

Dial, R.B. (1999) "Minimal Revenue Congestion Pricing Part I: A Fast Algorithm for the Single-Origin Case," Transportation Research Part B, 33: 189-202.

EPA (2006) Inventory of US Greenhouse Gas Emissions and Sinks (Accessed at http://www.epa.gov/climatechange/emissions/downloads06/06_Complete_Report.pdf, on April 30, 2007.)

FDOT (2003) 2002 Transportation Costs. Office of Policy Planning, Florida Department of Transportation.

Geller, H., P. Harrington, A.H. Rosenfeld, S. Tanishimad and F. Unander (2006) Policies for Increasing Energy Efficiency: Thirty years of Experience in OECD Countries. Energy Policy 34 (5): 556-573

Gilroy, L.C. (2007) NTTA's Proposal for SH-121, Is it Better than Cintra's? Commentary provided by the Reason Foundation. Accessed April 2008 from http://www.reason.org/commentaries/gilroy_20070511.shtml. 
Gulipalli, P. and K.M. Kockelman (2008) "Credit-Based Congestion Pricing: A Dallas-Fort Worth Application.” Transport Policy 15 (1): 23-32.

TRB (2001) Highway Capacity Manual 2000. Transportation Research Board, Washington, D.C.

Knight, F. (1924). "Some Fallacies in the Interpretation of Social Costs." Quarterly Journal of Economics. 38(4): 582-606.

Kalmanje, S. and K.M. Kockelman (2004) "Credit-Based Congestion Pricing: Travel, Land Value and Welfare Impacts,” Transportation Research Record 1864: 45-53.

Kockelman, K.M. (2004) Traffic Congestion. In Transportation Engineer's Handbook (Chapter 22). McGraw-Hill.

Kockelman, K.M. and S. Kalmanje (2005). "Credit-based congestion pricing: A policy proposal and the public's response." Transportation Research Part A, 39(7): 671-690.

Kockelman, K.M., K. Podgorski, M. Bina, and S. Gadda (2009) "Public Perceptions of Pricing Existing Roads and Other Transportation Policies: The Texas Perspective." Journal of the Transportation Research Forum 48 (3): 19-38.

Lemp, J.D. and K.M. Kockelman (2008) "Quantifying the External Costs of Vehicle Use: Evidence from America's Top-Selling Light-Duty Models.” Transportation Research Part D 13 (8): 491-504.

Lévy-Lambert, H. (1968) "Tarification des Services à Qualité Variable - Application aux Péages de Circulation," Econometrica, 36 (3-4), 564-574.

Litman, T. (2007) Transportation Cost Analysis: Techniques, Estimates and Implications. Victoria Transport Policy Institute. Victoria, BC, Canada.

Liu, L.N. and J.F. McDonald (1999) Economic Efficiency of Second-Best Congestion Pricing Schemes in Urban Highway Systems. Transportation Research Part B, 33, 157-188.

Marchand, M. (1968) "A Note on Optimal Tolls in an Imperfect Environment," Econometrica, 36 (3-4), 575-581.

Martin, W.A. and N.A. McGuckin (1998) Travel Estimation Techniques for Urban Planning. National Cooperative Highway Research Program (NCHRP) Report 365. National Research Council, Washington, D.C.

Maruyama, T. and A. Sumalee (2007) "Efficiency and equity comparison of cordon- and areabased road pricing schemes using a trip-chain equilibrium model." Transportation Research 41A (7): 655-671. 
Mohring, H. and M. Harwitz (1962) Highway Benefits: An Analytical Framework. Northwestern University Press, Evanston, IL.

Nakamura, K. and K.M. Kockelman (2002) "Congestion Pricing and Roadspace Rationing: An Application to the San Francisco Bay Bridge Corridor." Transportation Research 36A (5): 403417.

NJTA (2003) Statement of Revenues and Expenses for the Year Ended December 31, 2003, First Consolidated Toll Road Annual Report 2003, New Jersey Turnpike Authority.

NTTA (2003) Financial Statements and Supplementary Data 2003, North Texas Tollway Authority, Dallas North Tollway System.

Parry, I. W. H. and Q. Bento (2001) "Revenue Recycling and the Welfare Effects of Road Pricing," Scandinavian Journal of Economics, 103(4): 645-671.

Penchina, C.M. (2003) "Stability of Minimal Revenue Pricing." Paper presented at the $82^{\text {nd }}$ Annual Meeting of the Transportation Research Board, Washington, D.C.

Pigou, A.C. (1920). Wealth and Welfare. Macmillan, London.

Raux C., and G. Marlot (2005) "A System of Tradable CO2 Permits Applied to Fuel Consumption by Motorists," Transport Policy 12 (3): 255-265.

Samuel, P. (2007) The Role of Tolls in Financing $21^{\text {st }}$ Century Highways. Reason Foundation Policy Study 359.

SJHTCA (2003) Statement of Revenues, Expenses and Changes in Fund Net Assets (Deficit) for the Year Ended June 30, 2003, Annual Financial Report 2003, San Joaquin Hill Transportation Corridor Agency.

Small, K.A. and H.S. Rosen (1981) "Applied Welfare Economics with Discrete Choice Models," Econometrica, 49 (1): 105-130.

Small, K. (1992) "Using the Revenues from Congestion Pricing,” Transportation, 19: 359-381.

Small, K.A. and E.T. Verhoef (2007) The Economics of Urban Transportation. Routledge, London and New York.

Smith, A. (1976) An Inquiry into the Nature and Causes of the Wealth of Nations. London.

United States Department of Transportation (USDOT) (2006) Expert Forum on Road Pricing and Travel Demand Modeling Proceedings. Report No. DOT-OST/P-001-06. 
United States Government Accountability Office (U.S. GAO) (2006) Highway Finance: States' Expanding Use of Tolling Illustrates Diverse Challenges and Strategies, GAO Report to Congressional Requesters, June 2006.

Verhoef, E.T., P. Nijkamp, and P. Rietveld (1996) "Second-Best Congestion Pricing: The Case of an Untolled Alternative," Journal of Urban Economics, 40, 279-302.

Verhoef, E.T. (2000) "The Implementation of Marginal External Cost Pricing in Road Transport: Long Run vs. Short Run and First-Best vs. Second-Best," Papers in Regional Science, 79, 307332.

Verhoef, E.T. (2002a) "Second-Best Congestion Pricing in General Static Transportation Networks with Elastic Demands," Regional Science and Urban Economics, 32, 281-310.

Verhoef, E.T. (2002b) "Second-Best Congestion Pricing in General Networks: Heuristic Algorithms for Finding Second-Best Optimal Toll Levels and Toll Points," Transportation Research Part B, 36, 707-729.

Verhoef, E.T. and J. Rouwendal (2004) "Pricing, Capacity Choice, and Financing in Transportation Networks," Journal of Regional Science, 44 (3), 405-435.

Verhoef, E.T. (2007) "Second-Best Road Pricing through Highway Franchising," Journal of Urban Economics, 62, 337-361.

Vickrey, W.S. (1963) "Pricing in Urban and Suburban Transport," American Economic Review; Papers and Proceedings, 53: 452- 465.

Vickrey, W.S. (1969) "Congestion Theory and Transport Investment," American Economic Review; Papers and Proceedings, 59 (2), 251-260.

Viegas J. M. (2001). "Making Urban Road Pricing Acceptable and Effective: Searching for Quality and Equity in Urban Mobility." Transport Policy. 8(4): 289-294.

Walters, A.A. (1961) "The Theory and Measurement of Private and Social Cost of Highway Congestion,” Econometrica, 29 (4), 676-699.

Zhao, Y., K.M. Kockelman, and A. Karlstrom (2008) Welfare Calculations in Discrete Choice Settings: The Role of the Error Term Correlation. Proc'gs of the $87^{\text {th }}$ Annual Meeting of the Transportation Research Board and under final review for publication in Transport Policy, Washington, D.C. 


\section{FIGURES AND TABLES}

Figure 1: Network Layout

Figure 2: Nested Logit Model Structure with Associated Scale Parameters

Figure 3: Distribution of Low-VOTT Travelers Choosing Destination/Mode Combinations across Scenarios

Figure 4: Distribution of High-VOTT Travelers Choosing Destination/Mode Combinations across Scenarios

Table 1: Travel Times, Tolls, V/C Ratios, and VMT across Scenarios

Table 2: Shares of Travelers Choosing Destination B by TOD and Percentage Difference from No Toll, Build Scenario Share

Table 3: Revenues and Welfare Results by Scenario

Table 4: Overall Financial Results, for New Road Investment across Scenarios 
Figure 1: Network Layout

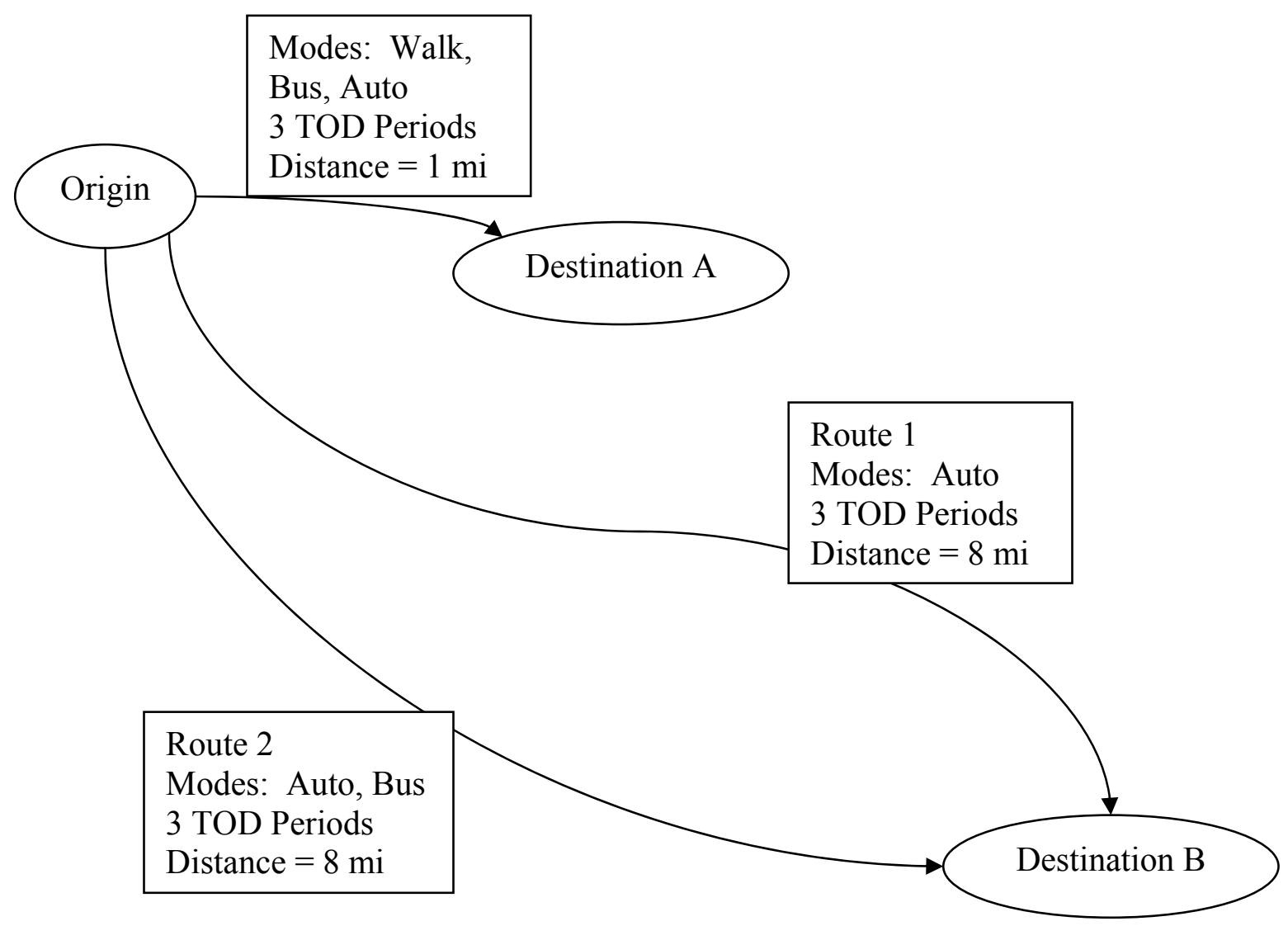


Figure 2: Nested Logit Model Structure with Associated Scale Parameters

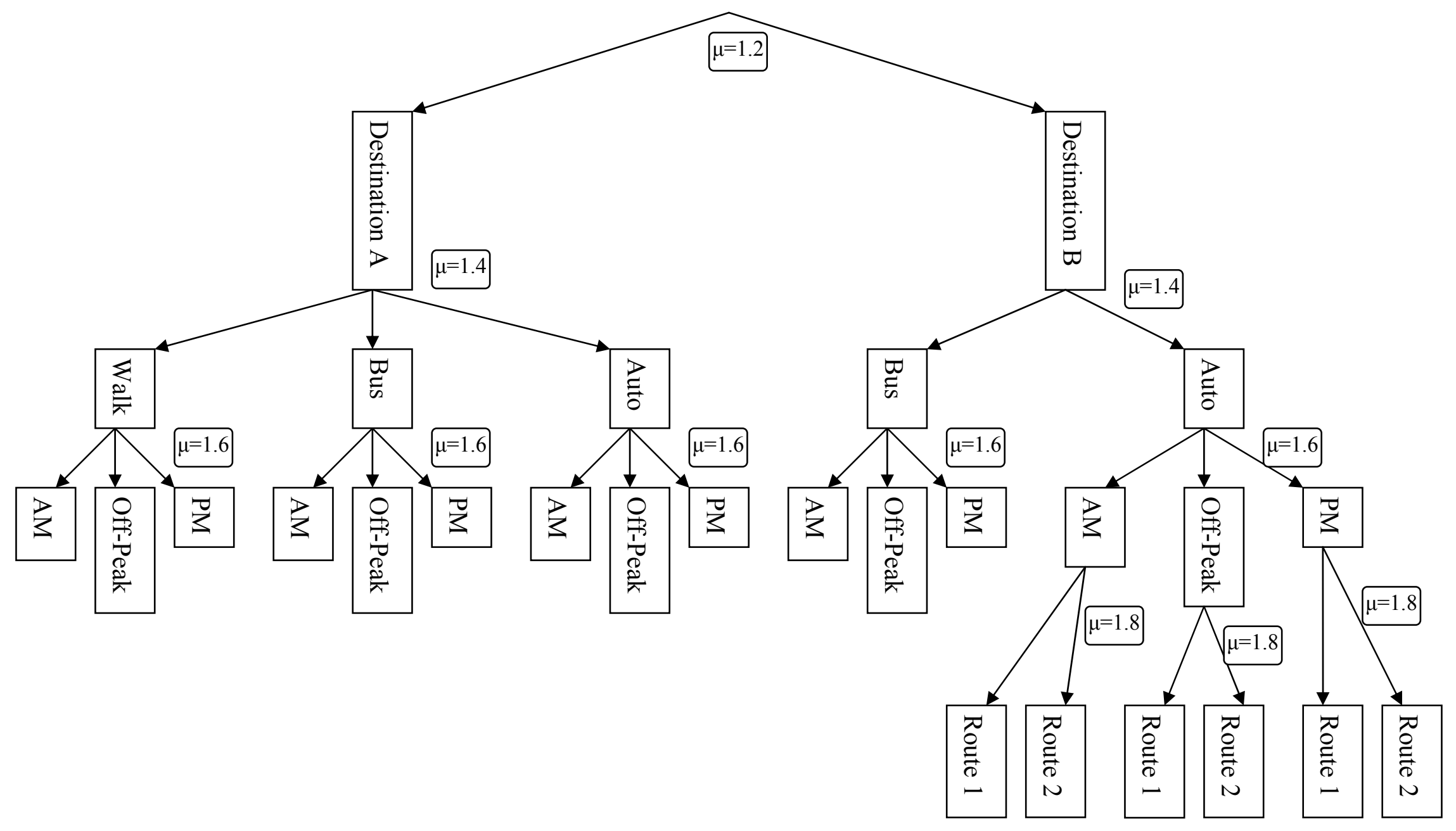


Figure 3: Distribution of Low-VOTT Travelers Choosing Destination/Mode Combinations across Scenarios

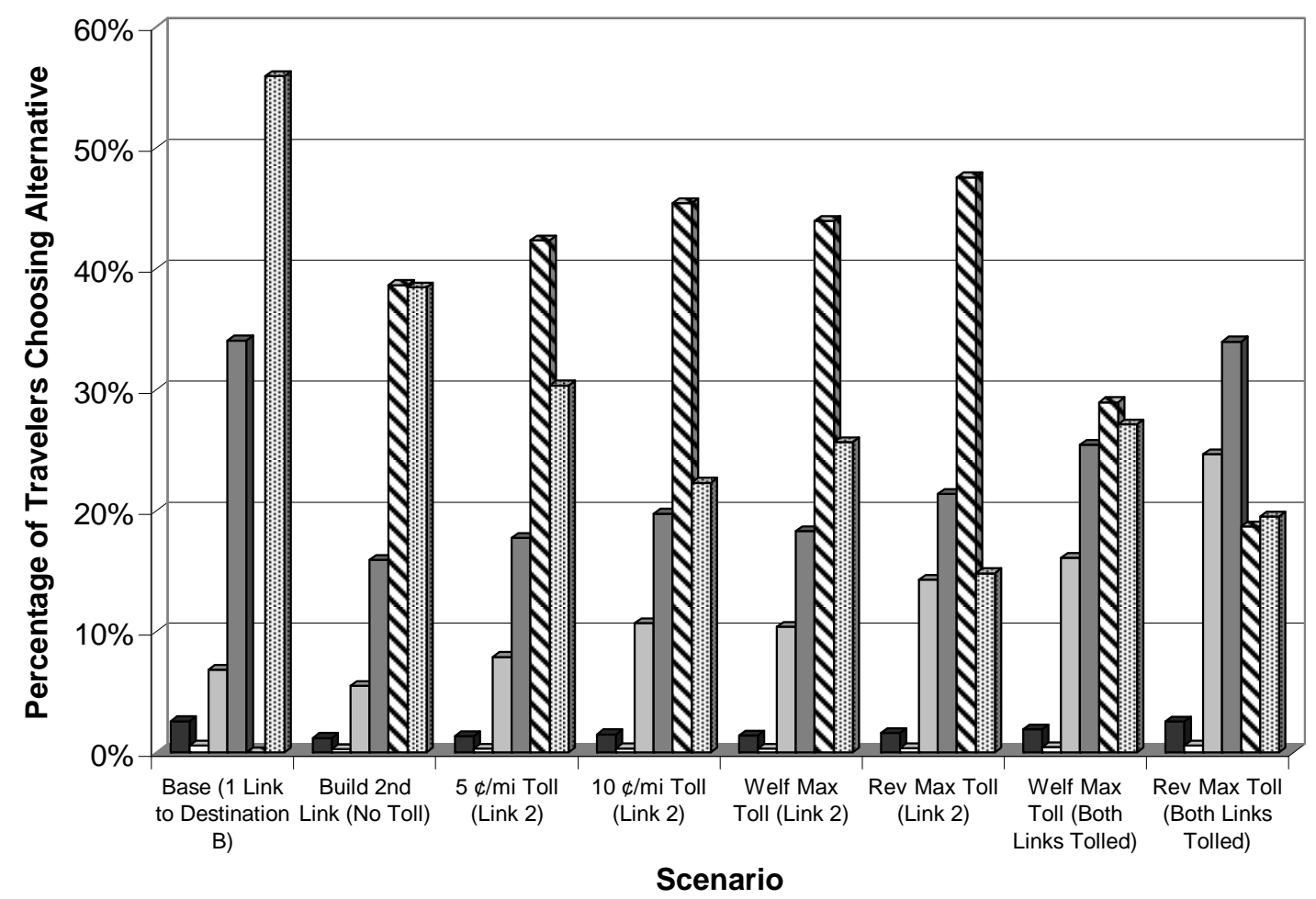

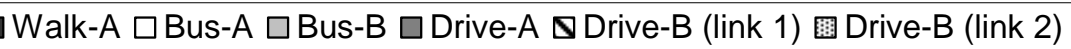


Figure 4: Distribution of High-VOTT Travelers Choosing Destination/Mode Combinations across Scenarios

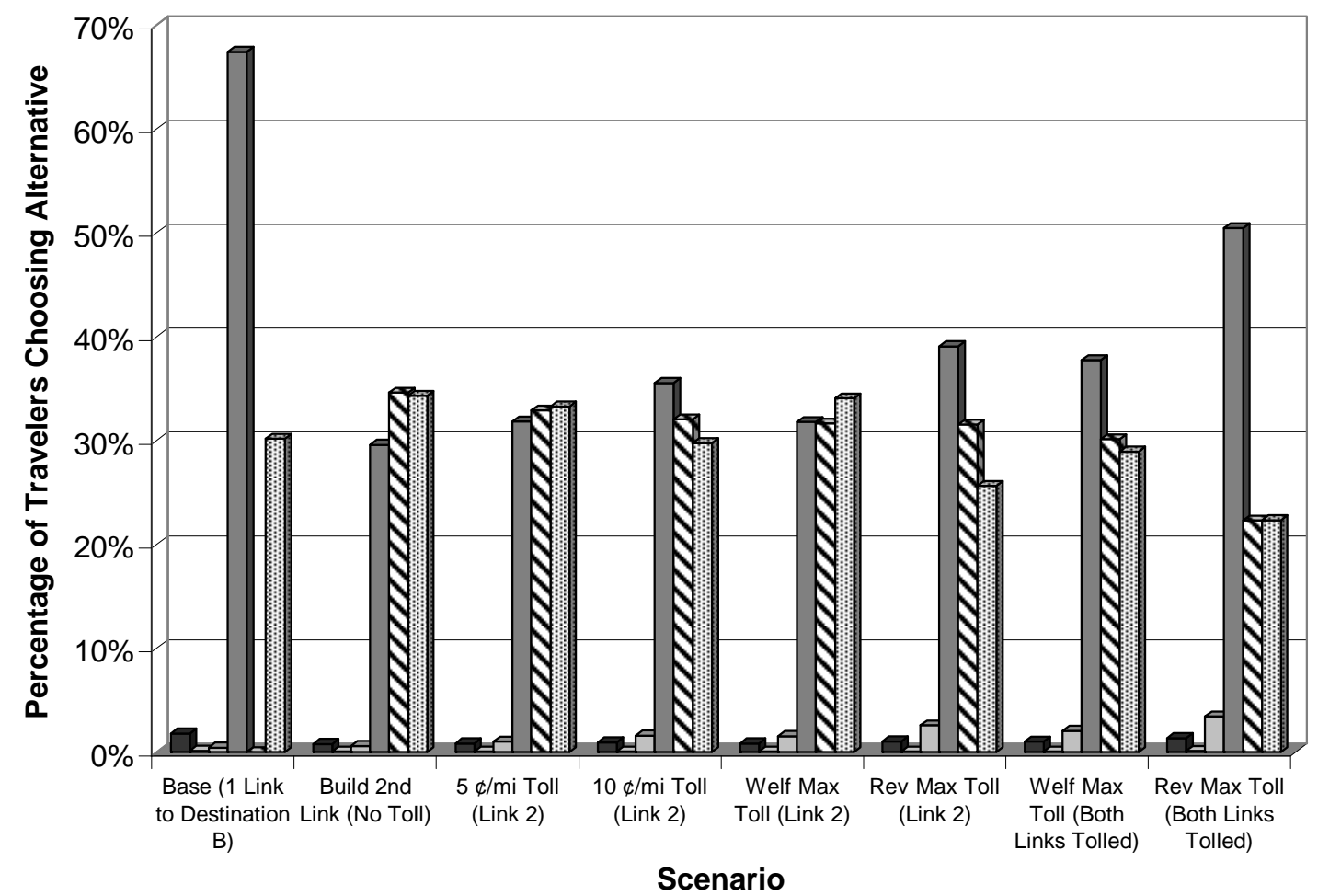

Walk-A $\square$ Bus-A $\square$ Bus-B $\square$ Drive-A $\Delta$ Drive-B (link 1) 围 Drive-B (link 2) 
Table 1: Travel Times, Tolls, V/C Ratios, and VMT across Scenarios

\begin{tabular}{|c|c|c|c|c|c|c|c|c|c|c|}
\hline & \multirow[b]{2}{*}{ Link } & \multirow[b]{2}{*}{ TOD } & \multirow{2}{*}{$\begin{array}{c}\text { Base (1 } \\
\text { Link to } \\
\text { Destination } \\
\text { B) } \\
\end{array}$} & \multirow[b]{2}{*}{$\begin{array}{c}\text { Build 2nd } \\
\text { Link (No } \\
\text { Toll) }\end{array}$} & \multicolumn{4}{|c|}{ Link 2 Tolled } & \multicolumn{2}{|c|}{ Both Links Tolled } \\
\hline & & & & & $\begin{array}{c}5 \text { cent } / \mathrm{mi} \\
\text { Toll }\end{array}$ & $\begin{array}{c}10 \text { cent } / \mathrm{mi} \\
\text { Toll }\end{array}$ & $\begin{array}{c}\text { Welfare } \\
\text { Maximizing } \\
\text { Toll } \\
\end{array}$ & $\begin{array}{c}\text { Revenue } \\
\text { Maximizing } \\
\text { Toll } \\
\end{array}$ & $\begin{array}{c}\text { Welfare } \\
\text { Maximizing } \\
\text { Toll } \\
\end{array}$ & $\begin{array}{c}\text { Revenue } \\
\text { Maximizing } \\
\text { Toll } \\
\end{array}$ \\
\hline \multirow{6}{*}{$\begin{array}{l}\text { Travel } \\
\text { Time } \\
\text { (min) }\end{array}$} & \multirow{3}{*}{ Link 1} & $\mathrm{AM}$ & 19.12 & 13.69 & 14.26 & 14.94 & 14.43 & 15.55 & 9.40 & 8.44 \\
\hline & & MID & 14.20 & 9.69 & 10.11 & 10.67 & 10.16 & 11.14 & 8.70 & 8.02 \\
\hline & & PM & 19.26 & 13.81 & 14.39 & 15.07 & 14.56 & 15.68 & 9.43 & 8.45 \\
\hline & \multirow{3}{*}{ Link 2} & $\mathrm{AM}$ & $\mathrm{N} / \mathrm{A}$ & 13.72 & 11.85 & 10.28 & 9.44 & 8.52 & 9.20 & 8.77 \\
\hline & & MID & $\mathrm{N} / \mathrm{A}$ & 9.71 & 8.51 & 8.06 & 9.00 & 8.03 & 8.67 & 8.03 \\
\hline & & $\mathrm{PM}$ & $\mathrm{N} / \mathrm{A}$ & 13.84 & 11.97 & 10.38 & 9.45 & 8.54 & 9.21 & 8.81 \\
\hline \multirow{6}{*}{ Toll (\$) } & \multirow{3}{*}{ Link 1} & $\mathrm{AM}$ & $\$ 0.00$ & $\$ 0.00$ & $\$ 0.00$ & $\$ 0.00$ & $\$ 0.00$ & $\$ 0.00$ & $\$ 1.13$ & $\$ 1.70$ \\
\hline & & MID & $\$ 0.00$ & $\$ 0.00$ & $\$ 0.00$ & $\$ 0.00$ & $\$ 0.00$ & $\$ 0.00$ & $\$ 0.58$ & $\$ 1.36$ \\
\hline & & PM & $\$ 0.00$ & $\$ 0.00$ & $\$ 0.00$ & $\$ 0.00$ & $\$ 0.00$ & $\$ 0.00$ & $\$ 1.14$ & $\$ 1.71$ \\
\hline & \multirow{3}{*}{ Link 2} & $\mathrm{AM}$ & N/A & $\$ 0.00$ & $\$ 0.40$ & $\$ 0.80$ & $\$ 0.89$ & $\$ 1.33$ & $\$ 1.20$ & $\$ 1.63$ \\
\hline & & MID & $\mathrm{N} / \mathrm{A}$ & $\$ 0.00$ & $\$ 0.40$ & $\$ 0.80$ & $\$ 0.26$ & $\$ 0.99$ & $\$ 0.60$ & $\$ 1.36$ \\
\hline & & $\mathrm{PM}$ & $\mathrm{N} / \mathrm{A}$ & $\$ 0.00$ & $\$ 0.40$ & $\$ 0.80$ & $\$ 0.91$ & $\$ 1.35$ & $\$ 1.21$ & $\$ 1.64$ \\
\hline \multirow{6}{*}{$\begin{array}{l}\mathrm{V} / \mathrm{C} \\
\text { Ratio }\end{array}$} & \multirow{3}{*}{ Link 1} & $\mathrm{AM}$ & $\mathrm{N} / \mathrm{A}$ & 0.97 & 0.99 & 1.00 & 0.99 & 1.02 & 0.75 & 0.61 \\
\hline & & MID & $\mathrm{N} / \mathrm{A}$ & 0.78 & 0.81 & 0.84 & 0.81 & 0.87 & 0.66 & 0.36 \\
\hline & & PM & $\mathrm{N} / \mathrm{A}$ & 0.97 & 0.99 & 1.01 & 0.99 & 1.02 & 0.75 & 0.61 \\
\hline & \multirow{3}{*}{ Link 2} & $\mathrm{AM}$ & 1.08 & 0.96 & 0.89 & 0.80 & 0.73 & 0.60 & 0.70 & 0.62 \\
\hline & & MID & 0.98 & 0.77 & 0.62 & 0.42 & 0.70 & 0.35 & 0.65 & 0.36 \\
\hline & & $\mathrm{PM}$ & 1.09 & 0.96 & 0.89 & 0.81 & 0.73 & 0.60 & 0.70 & 0.63 \\
\hline \multirow{4}{*}{$\begin{array}{c}\text { VMT } \\
\text { (veh- } \\
\text { mi/day) }\end{array}$} & \multirow{4}{*}{$\begin{array}{c}\text { All } \\
\text { Auto } \\
\text { Links }\end{array}$} & $\mathrm{AM}$ & 125,179 & 194,603 & 190,194 & 184,694 & 175,915 & 167,845 & 152,235 & 135,864 \\
\hline & & MID & 200,548 & 303,155 & 280,188 & 249,487 & 296,518 & 242,451 & 259,171 & 148,089 \\
\hline & & PM & 168,159 & 260,863 & 255,118 & 248,005 & 235,481 & 225,281 & 204,024 & 183,109 \\
\hline & & Total & 493,886 & 758,622 & 725,500 & 682,186 & 707,914 & 635,577 & 615,429 & 467,062 \\
\hline
\end{tabular}


Table 2: Shares of Travelers Choosing Destination B by TOD and Percentage Difference from No Toll, Build Scenario Shares

\begin{tabular}{|c|c|c|c|c|c|c|c|c|c|}
\hline \multirow[b]{2}{*}{$\begin{array}{l}\text { Destination } \\
\text { \& Route }\end{array}$} & \multirow[b]{2}{*}{ TOD } & \multirow[b]{2}{*}{ Percent } & \multirow[b]{2}{*}{$\begin{array}{c}\text { Build } \\
\text { 2nd Link } \\
\text { (No Toll) }\end{array}$} & \multicolumn{4}{|c|}{ One Link Tolled } & \multicolumn{2}{|c|}{ Both Links Tolled } \\
\hline & & & & $\begin{array}{l}5 \text { cent } / \mathrm{mi} \\
\text { Toll }\end{array}$ & $\begin{array}{l}10 \text { cent } / \mathrm{mi} \\
\text { Toll }\end{array}$ & $\begin{array}{c}\text { Welfare } \\
\text { Maximizing } \\
\text { Toll } \\
\end{array}$ & $\begin{array}{c}\text { Revenue } \\
\text { Maximizing } \\
\text { Toll } \\
\end{array}$ & $\begin{array}{c}\text { Welfare } \\
\text { Maximizing } \\
\text { Toll } \\
\end{array}$ & $\begin{array}{c}\text { Revenue } \\
\text { Maximizing } \\
\text { Toll } \\
\end{array}$ \\
\hline \multirow{6}{*}{$\begin{array}{l}\text { Destination } \\
\text { B, Both } \\
\text { Routes } \\
\text { Combined }\end{array}$} & & $\%$ of Travelers ${ }^{1}$ & 19.36 & 19.27 & 19.19 & 18.51 & 18.29 & 16.88 & 16.39 \\
\hline & AM Peak & $\begin{array}{c}\% \text { Decrease vs. No-Toll } \\
\text { Build Scenario }^{2}\end{array}$ & 0.00 & -0.46 & -0.84 & -4.39 & -5.51 & -12.79 & -15.30 \\
\hline & & $\%$ of Travelers ${ }^{1}$ & 30.79 & 28.82 & 25.97 & 30.32 & 25.34 & 27.12 & 16.95 \\
\hline & Off-Peak & $\begin{array}{c}\% \text { Decrease vs. No-Toll } \\
\text { Build Scenario }^{2} \\
\end{array}$ & 0.00 & -6.39 & -15.65 & -1.54 & -17.70 & -11.91 & -44.96 \\
\hline & & $\%$ of Travelers ${ }^{1}$ & 25.92 & 25.82 & 25.75 & 24.80 & 24.59 & 22.67 & 22.13 \\
\hline & PM Peak & $\begin{array}{c}\% \text { Decrease vs. No-Toll } \\
\text { Build Scenario }^{2} \\
\end{array}$ & 0.00 & -0.39 & -0.64 & -4.29 & -5.14 & -12.53 & -14.61 \\
\hline \multirow{6}{*}{$\begin{array}{l}\text { Destination } \\
\text { B, via } \\
\text { New Road }\end{array}$} & & $\%$ of Travelers ${ }^{1}$ & 9.22 & 8.53 & 7.68 & 7.04 & 5.74 & 6.70 & 6.00 \\
\hline & AM Peak & $\begin{array}{c}\% \text { Decrease vs. No-Toll } \\
\text { Build Scenario }^{2} \\
\end{array}$ & 0.00 & -7.48 & -16.69 & -23.58 & -37.73 & -27.29 & -34.94 \\
\hline & & $\%$ of Travelers ${ }^{1}$ & 14.83 & 11.86 & 8.03 & 13.42 & 6.78 & 12.39 & 6.87 \\
\hline & Off-Peak & $\begin{array}{c}\% \text { Decrease vs. No-Toll } \\
\text { Build Scenario }^{2}\end{array}$ & 0.00 & -20.00 & -45.81 & -9.47 & -54.25 & -16.44 & -53.68 \\
\hline & & $\%$ of Travelers ${ }^{1}$ & 12.34 & 11.43 & 10.32 & 9.39 & 7.70 & 8.95 & 8.06 \\
\hline & PM Peak & $\begin{array}{c}\% \text { Decrease vs. No-Toll } \\
\text { Build Scenario }^{2}\end{array}$ & 0.00 & -7.35 & -16.36 & -23.88 & -37.56 & -27.47 & -34.66 \\
\hline
\end{tabular}

${ }^{1}$ This is the total percentage of travelers choosing destination B and the given route and TOD.

${ }^{2}$ This is the percentage difference of the number of travelers choosing destination B and the given route and TOD as measured from the non-tolled new road scenario where all roads are non-tolled. 
Table 3: Revenues and Welfare Results by Scenario

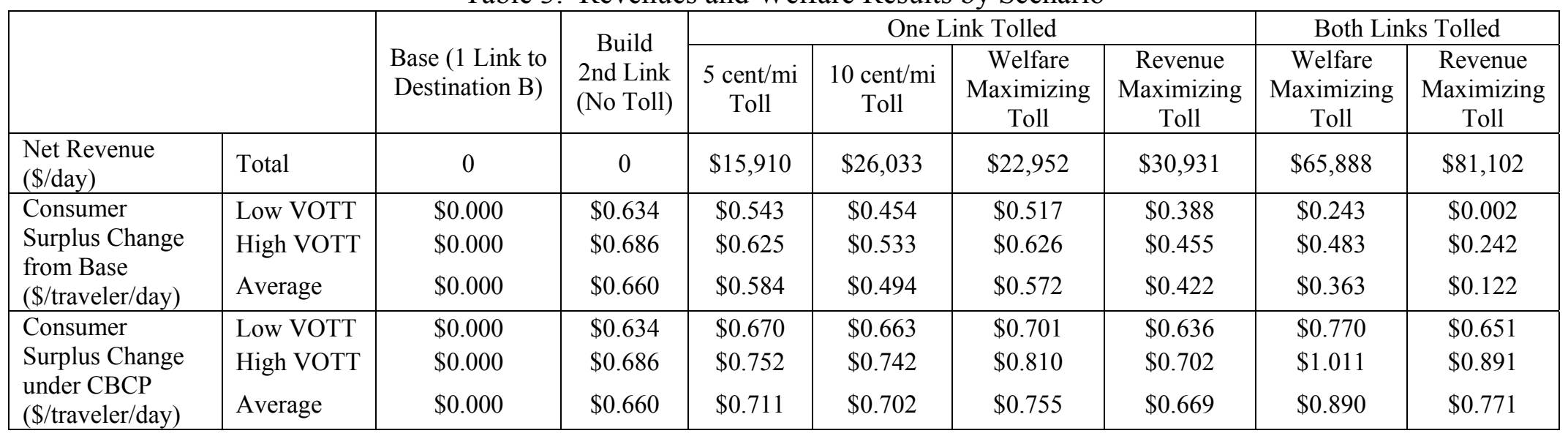


Table 4: Overall Financial Results, for New Road Investment across Scenarios

\begin{tabular}{|c|c|c|c|c|c|c|c|}
\hline & \multirow[b]{2}{*}{$\begin{array}{c}\text { Build } \\
\text { 2nd Link } \\
\text { (No Toll) }\end{array}$} & \multicolumn{4}{|c|}{ One Link Tolled } & \multicolumn{2}{|c|}{ Both Links Tolled } \\
\hline & & $\begin{array}{l}5 \text { cent } / \mathrm{mi} \\
\text { Toll }\end{array}$ & $\begin{array}{l}10 \text { cent } / \mathrm{mi} \\
\text { Toll }\end{array}$ & $\begin{array}{c}\text { Welfare } \\
\text { Maximizing } \\
\text { Toll } \\
\end{array}$ & $\begin{array}{c}\text { Revenue } \\
\text { Maximizing } \\
\text { Toll } \\
\end{array}$ & $\begin{array}{c}\text { Welfare } \\
\text { Maximizing } \\
\text { Toll } \\
\end{array}$ & $\begin{array}{c}\text { Revenue } \\
\text { Maximizing } \\
\text { Toll } \\
\end{array}$ \\
\hline 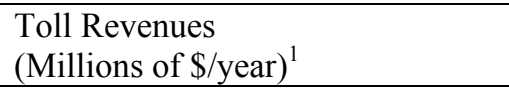 & $\$ 0$ & $\$ 4.98 \mathrm{M}$ & $\$ 8.15 \mathrm{M}$ & $\$ 7.18 \mathrm{M}$ & $\$ 9.68 \mathrm{M}$ & $\$ 20.62 \mathrm{M}$ & $\$ 25.38 \mathrm{M}$ \\
\hline $\begin{array}{l}\text { Roadway Maintenance Cost for } \\
\text { New Highway (Millions of } \$ / \text { year) }\end{array}$ & $\$ 0.224 \mathrm{M}$ & $\$ 0.224 \mathrm{M}$ & $\$ 0.224 \mathrm{M}$ & $\$ 0.224 \mathrm{M}$ & $\$ 0.224 \mathrm{M}$ & $\$ 0.224 \mathrm{M}$ & $\$ 0.224 \mathrm{M}$ \\
\hline $\begin{array}{l}\text { Toll Management Cost } \\
\text { (Millions of } \$ / \text { year) }\end{array}$ & $\$ 0$ & $\$ 0.8 \mathrm{M}$ & $\$ 0.8 \mathrm{M}$ & $\$ 0.8 \mathrm{M}$ & $\$ 0.8 \mathrm{M}$ & $\$ 1.6 \mathrm{M}$ & $\$ 1.6 \mathrm{M}$ \\
\hline $\begin{array}{l}\text { Net Revenue } \\
(\text { Millions of } \$ / \text { year) })^{2}\end{array}$ & $\$ 0$ & $\$ 3.96 \mathrm{M}$ & $\$ 7.12 \mathrm{M}$ & $\$ 6.16 \mathrm{M}$ & $\$ 8.66 \mathrm{M}$ & $\$ 18.80 \mathrm{M}$ & $\$ 23.56 \mathrm{M}$ \\
\hline $\begin{array}{l}\text { Repayment Time with 5\% } \\
\text { Discount Rate (years) }\end{array}$ & N/A & N/A & $16.9 \mathrm{yrs}$ & $21.5 \mathrm{yrs}$ & $12.7 \mathrm{yrs}$ & $4.9 \mathrm{yrs}$ & $3.8 \mathrm{yrs}$ \\
\hline $\begin{array}{l}\text { Additional Revenues with } 30 \text {-year } \\
\text { Loan at } 5 \% \text { (Millions of \$/year) }\end{array}$ & $-\$ 5.43 \mathrm{M}$ & $-\$ 1.25 \mathrm{M}$ & $\$ 1.92 \mathrm{M}$ & $\$ 0.96 \mathrm{M}$ & $\$ 3.45 \mathrm{M}$ & $\$ 13.59 \mathrm{M}$ & $\$ 18.36 \mathrm{M}$ \\
\hline $\begin{array}{l}\text { Credits Available } \\
(\$ / \text { traveler/weekday })^{5}\end{array}$ & $-\$ 0.139$ & $-\$ 0.032$ & $\$ 0.049$ & $\$ 0.024$ & $\$ 0.088$ & $\$ 0.347$ & $\$ 0.469$ \\
\hline $\begin{array}{l}\text { Net Traveler Welfare } \\
\text { (\$/average traveler/weekday) }^{6}\end{array}$ & $\$ 0.521$ & $\$ 0.552$ & $\$ 0.543$ & $\$ 0.596$ & $\$ 0.510$ & $\$ 0.711$ & $\$ 0.591$ \\
\hline
\end{tabular}

${ }^{1}$ Revenue generated for a year assumes 261 weekdays and 104 weekend days per year, where weekend-day revenues are one half those of regular weekdays.

${ }^{2}$ Net revenue is the difference between total revenue and the sum of maintenance and toll management costs.

${ }^{3}$ Repayment time is the time it takes to pay off an $\$ 80$ million loan using all of the net revenues generated by the scenario. Here, a discount rate for future revenues is assumed to be $5 \%$.

${ }^{4}$ Additional revenues are calculated as the difference between the net revenues and the annual ( $\$ 5.2$ million) payment on an $\$ 80$ million, 30 year loan with $5 \%$ interest.

${ }^{5}$ Credits available are the amount of credits available to be distributed to travelers per (effective) weekday. This calculation is based on the additional revenues, which is divided by the number of travelers $(125,000)$ and divided by the effective total number of weekdays per year (313).

${ }^{6}$ Net traveler welfare is simply the average welfare effect per traveler, before credits are distributed (as shown in Table 2),plus the credits available per person 